\title{
Presenilin1 Regulates Histamine Neuron Development and Behavior in Zebrafish, Danio rerio
}

\author{
Maria Sundvik, Yu-Chia Chen, and Pertti Panula \\ Neuroscience Center and Institute of Biomedicine/Anatomy, University of Helsinki, FIN-00014 Helsinki, Finland
}

Modulatory neurotransmitters, including the histaminergic system, are essential in mediating cognitive functions affected in Alzheimer's disease $(\mathrm{AD})$. The roles of disease genes associated with $\mathrm{AD}$, most importantly the presenilin1 gene (psen1), are poorly understood. We studied the role of psen 1 in plasticity of the brain histaminergic system using a novel psen 1 mutant zebrafish, Danio rerio. We found that in psen $^{-1-}$ zebrafish, the histaminergic system is altered throughout life. At $7 \mathrm{~d}$ postfertilization (dpf) the histamine neuron number was reduced in $p s e n 1^{-l-}$ compared with wild-type (WT) fish; at 2 months of age the histamine neuron number was at the same level as that in WT fish. In 1-year-old zebrafish, the histamine neuron number was significantly increased in psen $^{-1-}$ fish compared with WT fish. These changes in histamine neuron number were accompanied by changes in histamine-driven behaviors. Treatment with DAPT, a $\gamma$-secretase inhibitor, similarly interfered with the development of the histaminergic neurons. We also assessed the expression of $\gamma$-secretase-regulated Notch $1 a$ mRNA and $\beta$-catenin at different time points. Notch1 a mRNA level was reduced in $p s e n 1^{-1-}$ compared $^{-1}$ with WT fish, whereas $\beta$-catenin was slightly upregulated in the hypothalamus of $p s e n 1^{-1-}$ compared with WT fish at $7 \mathrm{dpf}$. The results reveal a life-long brain plasticity in both the structure of the histaminergic system and its functions induced by altered Notch1a activity as a consequence of psen 1 mutation. The new histaminergic neurons in aging zebrafish brain may arise as a result of phenotypic plasticity or represent newly differentiated stem cells.

\section{Introduction}

Alzheimer's disease $(\mathrm{AD})$ is the most common neurodegenerative disorder characterized by cognitive decline and dementia (Bishop et al., 2010). The cognitive decline in AD is associated with significant reduction in subcortical modulatory inputs, including the cholinergic (Whitehouse et al., 1982) and the histaminergic (Saper and German, 1987; Airaksinen et al., 1991; Panula et al., 1998) ones. Histamine is a biogenic amine discovered a century ago (Dale and Laidlaw, 1910). In the CNS, histamine is confined to neurons of the tuberomammillary nucleus (Panula et al., 1984; Ekström et al., 1995; Eriksson et al., 1998). The histaminergic neurotransmitter system is involved in different functions from cognition to hormonal regulation (Haas and Panula, 2003; Haas et al., 2008). Postmortem studies of the his-

\footnotetext{
Received April 13, 2012; revised Nov. 5, 2012; accepted Nov. 9, 2012

Author contributions: M.S., Y.-C.C., and P.P. designed research; M.S. and Y.-C.C. performed research; M.S., Y.C.C., and P.P. analyzed data; M.S., Y.-C.C., and P.P. wrote the paper.

This study was funded by the Academy of Finland (Grants No 116177 and 207352, http://www.aka.fi/en-GB/A/), the Finnish Technology Development Fund (TEKES, http://www.tekes.fi/en/community/Home/351/Home/473), the Sigrid Juselius Foundation (http://www.sigridjuselius.fi/foundation) and The Magnus Ehrnrooth Foundation (http://pro.tsv.fi/magnusehrnrooth/English/). Maria Sundvik was supported by the Helsinki Biomedical Graduate Program (http://www.hbgs.helsinki.fi/HBGS_2/Home.html). The funders had no role in study design, data collection and analysis, decision to publish, or preparation of the manuscript. We thank Henri Koivula and Susanna Norrbacka for excellent fish care and Anna Lehtonen for technical assistance. We thank Dr. Dana Zivkovic (Hubrecht Institute, Developmental Biology and Stem Cell Research, KNAW, and University Medical Center Utrecht, The Netherlands) for the psen $1^{-/-}$mutant fish line and Dr. Michael Brand (Biotechnology Center (BIOTEC), Technical University (TU) Dresden, Dresden, Germany) for the Notch1a plasmid.

Correspondence should be addressed to Prof. Pertti Panula, Neuroscience Center and Institute of Biomedicine, University of Helsinki, P.0. Box 63, University of Helsinki, FIN-00014 Helsinki, Finland. E-mail: pertti.panula@helsinki.fi.

DOI:10.1523/JNEUROSCI.1802-12.2013

Copyright $\odot 2013$ the authors $\quad 0270-6474 / 13 / 331589-09 \$ 15.00 / 0$
}

taminergic neurotransmitter system in $\mathrm{AD}$ brains have shed light on the role of histamine in brain and found that histamine is reduced in $\mathrm{AD}$ patients (Panula et al., 1998). Histamine improves cognitive performance (Medhurst et al., 2007), and histamine H3 receptor ligands are attractive drug candidates (Schwartz, 2011; Tiligada et al., 2011). Patients with inherited early onset AD [familial AD (FAD)] carry mutations mainly within the genes for presenilin1 (PSEN1), presenilin2 (PSEN2), and amyloid precursor protein (APP) (Tanzi and Bertram, 2005). PSEN1 is associated with the $\gamma$-secretase complex (Kimberly et al., 2003) within the neuronal membranes (Kovacs et al., 1996; Xu et al., 2002; Hansson et al., 2004). PSEN1 in the $\gamma$-secretase complex has many functions, including cleavage of APP (Borchelt et al., 1996), regulation of $\mathrm{Ca}^{2+}$ homeostasis (Guo et al., 1996; Stutzmann et al., 2004), cleavage of the Notch receptor (Levitan and Greenwald, 1995; De Strooper et al., 1999; Jack et al., 2001), and involvement in Wnt/ $\beta$-catenin signaling (Serban et al., 2005). PSEN1 affects the proliferation of cells in the CNS both in the hippocampus and subventricular zone of two different transgenic mouse models of AD (Wen et al., 2002; Rodríguez et al., 2009) via Notch signaling (Veeraraghavalu et al., 2010). PSEN1 also functions outside the $\gamma$-secretase complex, and the ability to degrade $\beta$-catenin is one example (De Strooper and Annaert, 2010). Histamine has been implicated as a neurogenesispromoting factor; an in vitro study (Molina-Hernández and Velasco, 2008) showed that histamine induces neuronal stem cell proliferation through histamine $\mathrm{H} 2$ receptor and promotes neuronal fate through histamine $\mathrm{H} 1$ receptor. Zebrafish has established itself as a model organism within neurosciences (Panula et al., 2010). In zebrafish, the histaminergic neurotransmitter sys- 
A >gi|56790305|ref|NP_571099.1| presenilin 1 [Danio rerio]

MADLVQNAANNVLNDGMDT SRHTS STAAPPSRNEVELNGQPP TAP P PQVVTDSEEDEDEELTLKYGAKHV IMLE IPVTLCMVVVVAT IKSVS FY TQ KD GQQLIYTP FREDTE TVGQRALHSML NA I IMISVIVVMT LVLV VL YKYRCY KVI OAWL FF SNLLLLF FESL IYLGEVFKT YNVAMDY FT LAL I IWN FGVV GMICI HWKG PL RL QQAYLIMI SALMALV FI KY LPEWT AWLI LAA ISVY DLLAVLC PKGP LR ILVET AQERNEA I FPALI YS ST MVWL FNMADSA ET RNNSSH PVPQQ ENQVVAMAP TAQAEDDGG FT PAWV DHQQHQLGP MQS TEESRRQIQE MP SARP PP PAD DDEE RGVKLGLGD FI FY SMLVGKASA TASGDWNTTLACEVAILI GLCLTLLLLAI FKKA LPALPISITFGLVEY FATDNLVRP FMDQ LAVHQFY I

\begin{tabular}{|c|c|c|c|}
\hline uery: & 1 & \multirow{2}{*}{\multicolumn{2}{|c|}{ GTTCAAGAC GTATAACGTGGCGATGGATTACTTCACGCTGGCGTTGATCATCTGGAACTT }} \\
\hline & & & \\
\hline Hit: & 599 & GTTCAAGACGTATAACGTGGCGATGGATTACTTCACGCTGGCGTTGATCATCTGGAACTT & 658 \\
\hline Query: & 61 & 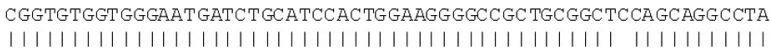 & 20 \\
\hline Hit: & 659 & CGGTGTGGT GGGAAT GATCT GCATCCACTGGAAGGGGCCGCTGCGGCTTCAGCAGGCCTA & 718 \\
\hline Query: & 121 & 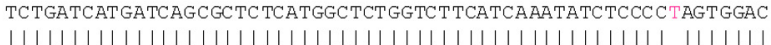 & 180 \\
\hline Hit: & 719 & TCTGATCAT GATCAGCGCTC TCATGGCTCT GGTCT TCATCAAATATCTCCCCGAGT GGAC & 778 \\
\hline Query: & 181 & $\begin{array}{l}\text { CGCATGGCTCATCCTCGCTGCTATTTCAGTCTACGGTC } \\
11111111111111111111111111111111111\end{array}$ & \\
\hline Hit: & 779 & CGCATGGCTCATCCTCGCTGCTATTTCAGTCTACGATC & \\
\hline
\end{tabular}

B
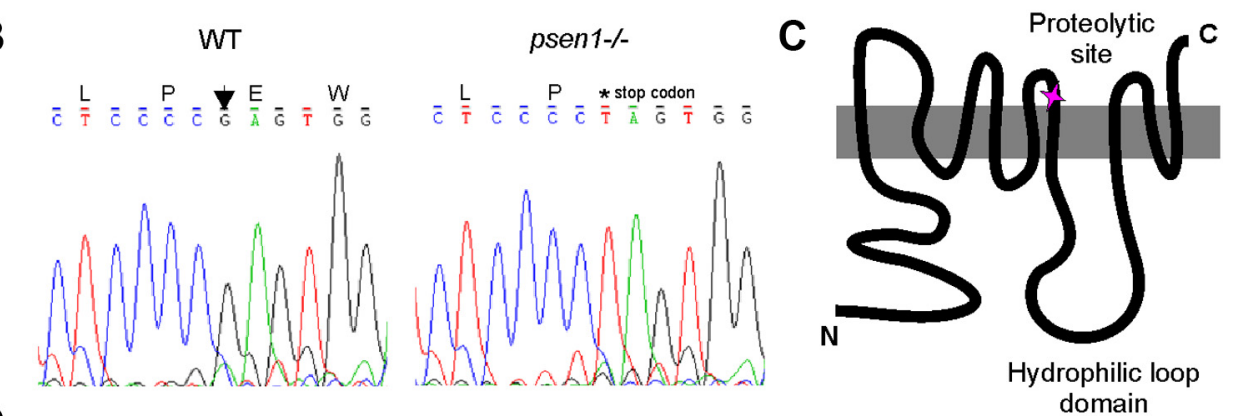

D
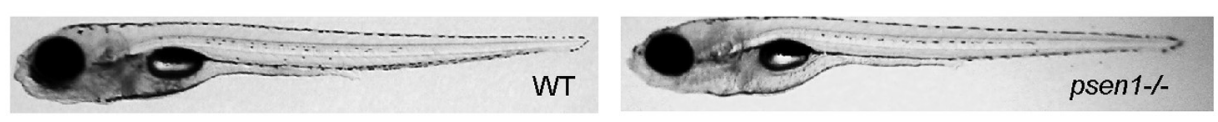

Figure 1. Identification of mutation leading to production of truncated PSEN1.A, $B$, A point mutation in exon 5 induces a premature stop codon. $C$, Structure of the transmembrane regions of PSEN1. The mutation in $p s e n 1^{-1-}$ fish is indicated with a star on amino acid E within the third extracellular loop. The image is modified (Dillen and Annaert, 2006). D, Gross phenotype of psen $1^{-/-}$ and WT fish at $7 \mathrm{dpf}$.

tem, including its receptors, is highly similar to that of other vertebrates, and histamine receptor ligands affect behavior in both adult and larval zebrafish (Peitsaro et al., 2003; Peitsaro et al., 2007). PSEN1 is conserved in many species, including zebrafish (Leimer et al., 1999). We hypothesized that the histaminergic system might be affected during the development of zebrafish carrying a mutation in a FAD-associated disease gene, psen1. We identified psen 1 as a regulator of the development of histaminergic neurons in a complex manner and found behavioral alterations that match the changes observed in histaminergic neurotransmission in $p s e n 1^{-/-}$fish.

\section{Materials and Methods}

Animals. The permits for the experiments were obtained from the Office of the Regional Government of Southern Finland in agreement with the ethical guidelines of the European convention. The wild-type (WT) animals used for this study were of the TL strain, and $p \operatorname{sen} 1^{-1-}$ fish (PS1 hu2547) were made in a TL background by TILLING at the Hubrecht Laboratory (Utrecht, The Netherlands). The mutation was identified by RT-PCR and sequencing as described below. This fish strain was a kind gift from Dr. Dana Zivkovic (Hubrecht Institute, Utrecht, The Netherlands). The experiments were done on either sex. The gender effect was not taken into account when assessing the histaminergic system, as no significant difference between sexes has been found (Sundvik and Panula, 2012).

Behavioral assay. To assess the effect of histamine on behavior, two behavioral assays were used. First the basic locomotor activity and place preference was observed during $10 \mathrm{~min}$ in both larvae (6-well plate) and adult zebrafish. This method has been described earlier (Peitsaro et al., 2003; Panula et al., 2006; Peitsaro et al., 2007). In the second behavioral test we studied whether light per se affects the activity of the mutant fish as has been observed in histidine decarboxylase $(h d c)$ morphant fish (Sundvik et al., 2011). The response to light of psen1 mutants was assessed by observing $6 \mathrm{~d}$ postfertilization (dpf) fish during 2 min periods of lights on and off for a period of $30 \mathrm{~min}$. All data were further analyzed with the EthoVision software (Noldus Information Technologies) and GraphPad Prism (GraphPad Software).

Genotyping. DNA was isolated from fin clips of adult zebrafish with SZL buffer and stored at $-80^{\circ} \mathrm{C}$ until further processing. Standard touchdown RT-PCR was used for verifying the mutation in psen 1 hu 2547 fish. The following primers were used: GAAACCCATTTGGGAAGTG and AATACAAGCCTACACACAACC for the first RT-PCR and primers AGGAAACAGCTATGACCAT GAACGCAGAAGAATGAACG and TGTAAAACGACGGCCAGT CAAGTTTGACATTTGCATGG for the second RT-PCR.

Immersion with DAPT. DAPT ( $N$-[(3,5-difluorophenyl)acetyl $]-\mathrm{L}-$ alanyl-2-phenyl]glycine-1,1-dimethylethyl ester) in solution (Tocris Bioscience) was diluted in DMSO to reach a final concentration of 2.5 $\mathrm{mm}$. At $1 \mathrm{dpf}, 30$ fish per treatment group were dechorionated and moved to 6-well plates and kept in $3 \mathrm{ml}$ of embryo medium (E3; $5 \mathrm{~mm} \mathrm{NaCl}, 0.17$ $\mathrm{mm} \mathrm{KCl}, 0.33 \mathrm{~mm} \mathrm{CaCl}_{2}, 0.33 \mathrm{~mm} \mathrm{MgSO}_{4}$; all reagents were from SigmaAldrich) containing either $1 \%$ DMSO or DAPT.

RNA isolation and quantitative RT-PCR. RNA was isolated from 10 or 30 pooled $7 \mathrm{dpf}$ larvae for a single sample. The RNA was isolated by 
RNeasy Mini Kit (Qiagen). RNA quality and amount were analyzed spectrophotometrically and cDNA was prepared by SuperScript III (Invitrogen). Primers used for quantitative RT-PCR were galanin (forward, GA CCAACTGATACTCAGGATGCA; reverse, ATCCCGAGTGTTTCTGT CAGAA) and $\beta$-actin (forward, CGAGCAGGAGATGGGAACC; reverse, CAACGGAAACGCTCATTGC) (Keegan et al., 2002).

In situ hybridization. In situ hybridization was preformed according to the protocol of Thisse and Thisse (Thisse and Thisse, 2008) with several modifications as described previously (Chen et al., 2009; Kudo et al., 2009). $h d c$ probe was produced as described (Sundvik et al., 2011). The Notchla plasmid was a kind gift from Dr. Michael Brand (Biotec, Biotechnology Center TU Dresden, Dresden, Germany). Notchla RNA digoxigenin-labeled probes were produced according to the abovementioned protocols using XbaI (BioLabs Inc.), and in situ hybridization was preformed following standard in situ hybridization protocols (Thisse and Thisse, 2008).

Immunohistochemistry. Immunohistochemistry on both larvae and adults was done following the protocol outlined in (Kaslin and Panula, 2001). The following antibodies were used: rabbit anti-histamine 19C, 1:10000 (Panula et al., 1990); rabbit anti-active caspase-3, 1:500 (clone C92-605, catalog no. 559565, BD Biosciences); mouse anti-tyrosine hydroxylase 1, 1:1000 (LOT22941, DiaSorin); rabbit anti-galanin, 1:10001:5000 (catalog no. AB1985/AB5909, Millipore); rabbit anti- $\beta$-catenin, 1:1000 (clone 2206, LOT056K4763, Sigma-Aldrich); rat anti-serotonin, 1:250 (MAB352, Millipore); the secondary antibodies were the highly cross-purified Alexa Fluor-conjugated antibodies (488 or 568 fluorophores, Invitrogen). The use of these primary antibodies in zebrafish has been reported elsewhere: rabbit anti-histamine 19C (Eriksson et al., 1998); rabbit anti-active caspase-3 (Kratz et al., 2006); mouse antityrosine hydroxylase 1 and rat anti-serotonin (Kaslin and Panula, 2001); anti-galanin (Sundvik and Panula, 2012); rabbit anti- $\beta$-catenin (Matsuda and Chitnis, 2009; Tallafuss et al., 2009). As all of the histamine neurons are located extremely ventrally in the hypothalamus, we carried out whole mount immunostaining of whole adult brains to visualize the entire three-dimensional structure and to obtain true numbers at histamine-immunoreactive neurons as described in detail (Sundvik and Panula, 2012).

Microscopy and image analysis. An inverted light microscope, Leica DM IRB, with Leica Application Suite, MultiFocus option (Leica Microsystems $\mathrm{GmbH}$ ) was used to acquire pictures of the samples where the mRNA expression was detected by in situ hybridization. A confocal microscope, Leica TCS SP2 AOBS, was used to visualize and quantify the histaminergic system detected by immunohistochemistry in both larval and adult zebrafish brains, as well as the immunoreactivity for caspase-3, tyrosine hydroxylase 1, galanin, serotonin, and $\beta$-catenin. Excitation wavelength for samples with Alexa Fluor 488 fluorophore was $488 \mathrm{~nm}$, and the emission was collected from 500 to $550 \mathrm{~nm}$. The excitation wavelength used for samples stained with Alexa Fluor 568 fluorophore was $561 \mathrm{~nm}$, and the emission was collected at $600-700 \mathrm{~nm}$. Maximum projection images of the acquired stacks were produced with Leica software to render the 3D material 2D. Quantification of the neuron numbers in the $3 \mathrm{D}$ material was done in Fiji software. All pictures were collected into panels in CorelDraw (Corel).

Statistical methods. Comparisons between two groups were done with Student's $t$ test. Comparisons between several groups were done with one-way ANOVA, two-way ANOVA, and repeated measures two-way ANOVA with appropriate post hoc tests. The data in graphs were presented as mean \pm SEM.

\section{Results}

Genotyping

The zebrafish psen1-null mutant was identified with TILLING (Wienholds et al., 2003) by Dr. Dana Zivkovic's Laboratory at Hubrecht Institute, Developmental Biology and Stem Cell Research, Royal Netherlands Academy of Arts and Sciences and University Medical Center Utrecht, The Netherlands. The mutation was localized to exon 5 where it induced a point mutation resulting in a premature stop codon by exchanging a
A
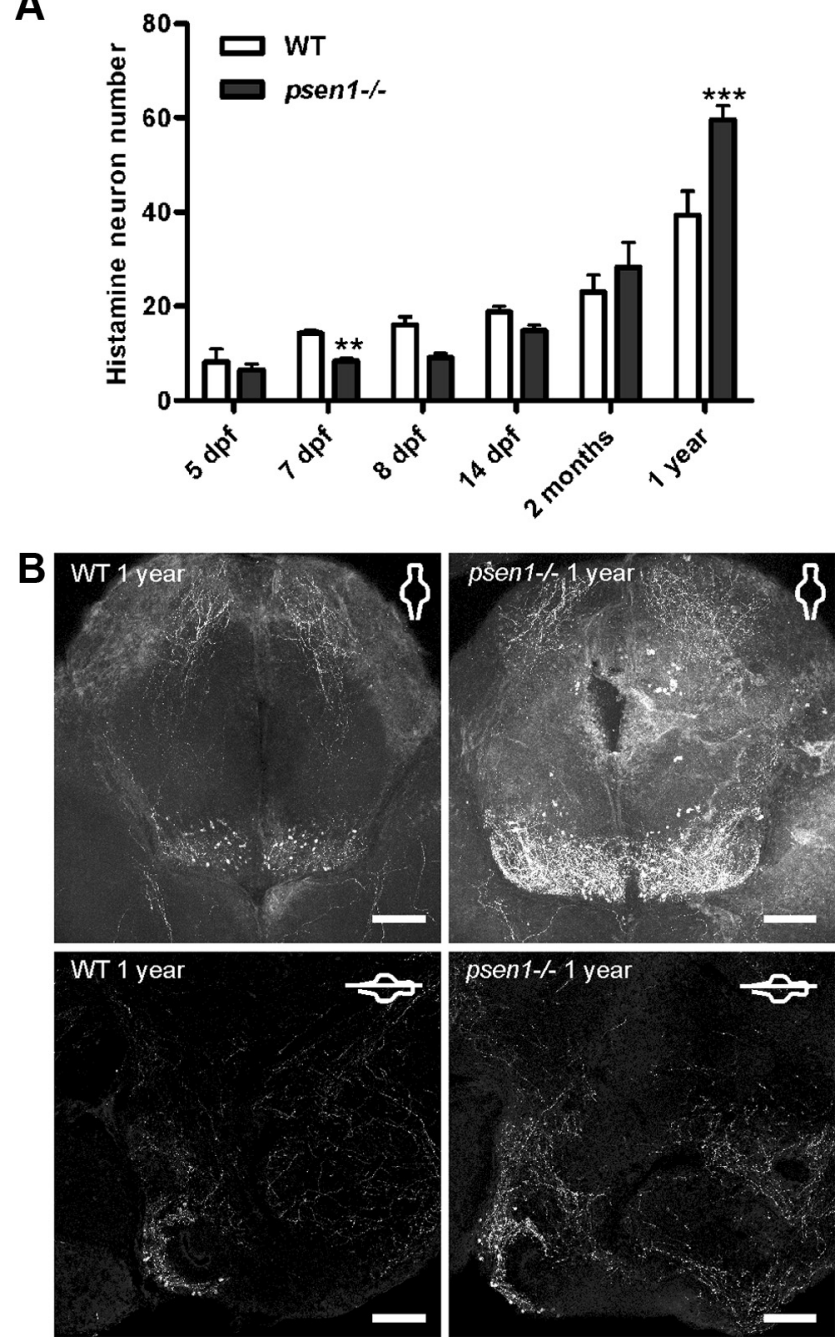

Figure 2. The histaminergic neurons at different ages in $p \operatorname{sen} 1^{-1-}$ and WT zebrafish. $\boldsymbol{A}$, Histamine neuron numbers at different ages. The graph shows mean values \pm SEM ( $5 \mathrm{dpf}, n=$ $4-6 ; 7 \mathrm{dpf}, n=31-32 ; 8 \mathrm{dpf}, n=5 ; 14 \mathrm{dpf}, n=11-12 ; 2$ months old, $n=4-5 ; 1$ year old, $n=11$; significance between genotypes is only shown at specific time points; ${ }^{* *} p \leq 0.01$, ${ }^{* * *} p \leq 0.001$, two-way ANOVA, Bonferroni post hoc test). $\boldsymbol{B}$, The top panels are from whole mount brains of 1-year-old psen $1^{-1-}$ and WT fish, and the bottom panels are sagittal sections of fish of the same age. Whole mounts were used to enable counting of the total neuron number, and sections were used to visualize the extremely ventral and superficial location of all the histaminergic neurons. Scale bar, $100 \mu \mathrm{m}$.

guanine to thymine in the codon that in normal cases codes for glutamic acid (Fig. 1A,B). The truncated protein in the mutants lacks the proteolytic site of PSEN1 and the C terminus (Fig. 1C). The gross phenotype of the $p \operatorname{sen} 1^{-1-}$ fish was normal (Fig. 1D) at $7 \mathrm{dpf}$. As these individuals were viable and developed normally to adulthood in contrast to the mouse psen 1 knockout animals (Shen et al., 1997), the psen 1 mutant fish offers an excellent tool to understand the role of psen 1 in development and neural functions.

\section{Development of the histaminergic system from larvae to adulthood in $p \operatorname{sen} 1^{-/-}$}

The histamine-immunoreactive neurons were counted at different ages of larval and adult fish (Fig. 2A). A significant interaction between time and genotype was found (two-way ANOVA, $p<$ $0.0001, F=13.40, \mathrm{DF} n=5, \mathrm{DF} d=125$, where $n$ is numerator and $d$ is denominator of the degrees of freedom, DF). No signif- 


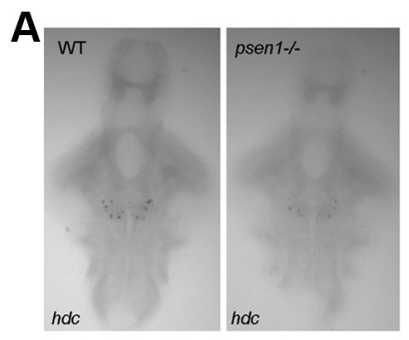

C
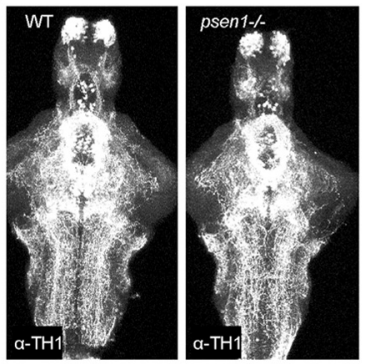

E
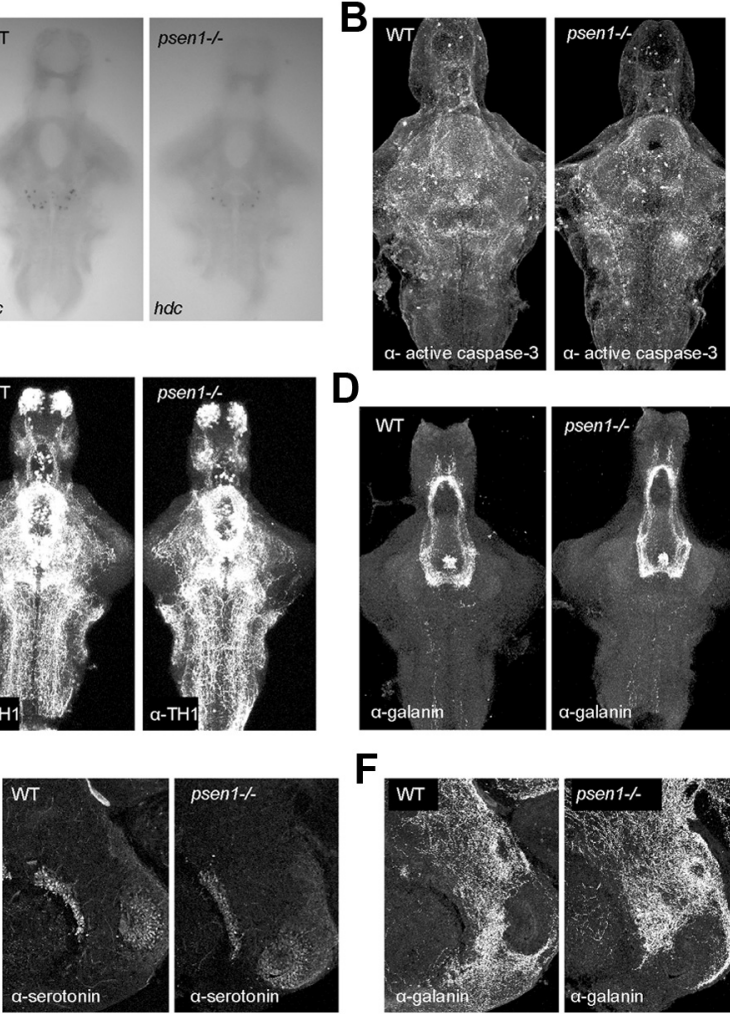

D
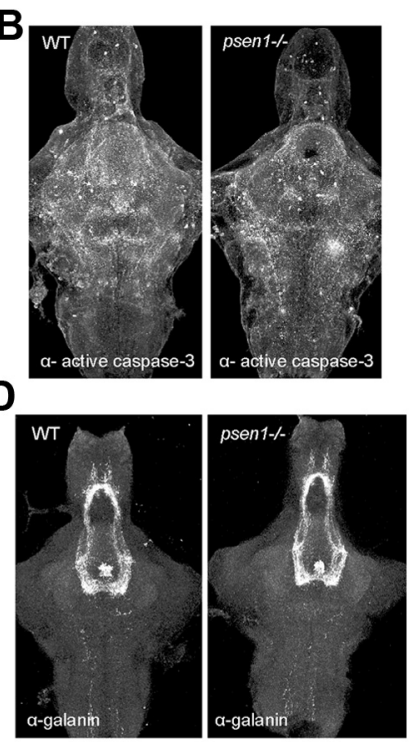

$\mathbf{F}$

Figure 3. Neurotransmitter systems in $p$ sen $1^{-1-}$ and WT zebrafish. $A$, Representative images of $h d c$ mRNA expression in $7 \mathrm{dpf}$ fish brains. $\boldsymbol{B}$, Active caspase-3 immunoreactivity in $7 \mathrm{dpf}$ fish brain, $n=10$. C, Tyrosine hydroxylase 1 (TH1) immunoreactivity in $7 \mathrm{dpf}$ fish brain, $n=$ 6-8.D, Galanin immunoreactivity in $7 \mathrm{dpf}$ fish brain, $n=14 . \boldsymbol{E}$, $\boldsymbol{F}$, Serotonin immunoreactivity $(\boldsymbol{E})$ and galanin $(\boldsymbol{F})$ immunoreactivity were unaltered in the posterior hypothalamus in both genotypes at adult stage ( $\sim 2.5$ years $), n=3$.

icant difference was observed in the number of histamine neurons between the WT and $p \operatorname{sen} 1^{-1-}$ fish at $5 \mathrm{dpf}$, but at $7 \mathrm{dpf}$ the histamine neuron number in $p s e n 1^{-1-}$ fish was significantly lower compared with that of WT fish (two-way ANOVA, Bonferroni post test, $\left.{ }^{* *} p \leq 0.01\right)$. At 2 months of age, just before the fish reach sexual maturity, no significant difference was observed between the $p s e n 1^{-1-}$ and WT fish. In a sagittal view of the adult brain (Fig. $2 B$, bottom) it was possible to observe the location and morphology of the histaminergic neuron population. Imaging all neuron populations throughout the entire whole mount adult brains is not possible at the moment, but imaging the entire histaminergic neuron population was possible because the depth (ventral to dorsal) of the system is about $200 \mu \mathrm{m}$. This approach allowed us to quantify the histamine neuron number in the brain without sectioning, and thus reveal the complete threedimensional structure of the nucleus. When histamine neuron number was counted in the brains of 1-year-old zebrafish, a significantly higher (about 30\%) number of histamineimmunoreactive neurons was observed in $p s e n 1^{-1-}$ fish compared with WT fish (two-way ANOVA, Bonferroni post hoc test, ${ }_{* * *} p \leq 0.001$, Fig. $\left.2 A, B\right)$. We further assessed the expression of $h d c$ mRNA by in situ hybridization in $7 \mathrm{dpf}$ larval brains. These results (Fig. $3 A$ ) confirmed the findings observed in the immunostained brains; at $7 \mathrm{dpf}$ there were significantly fewer cells expressing $h d c$ mRNA in $p s e n 1^{-1-}$ fish than in WT fish (Student's $t$ test, $p \leq 0.001, n=24$ /group). This lower number of histaminergic neurons was not associated with apoptotic cell death, as activated caspase- 3 immunohistochemistry could not show any
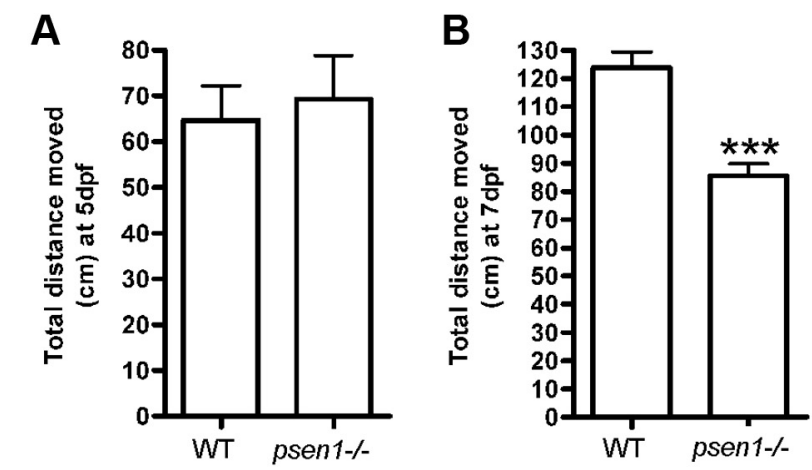

C

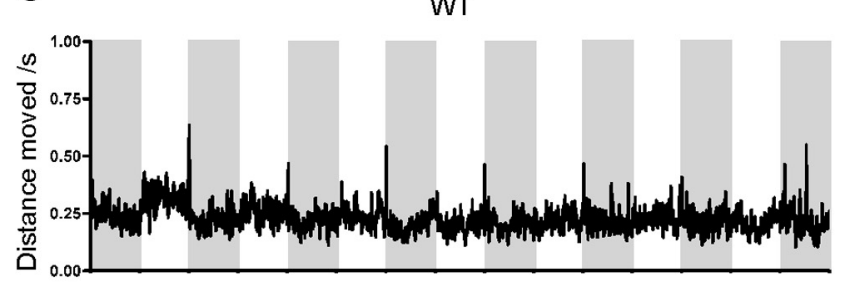

D

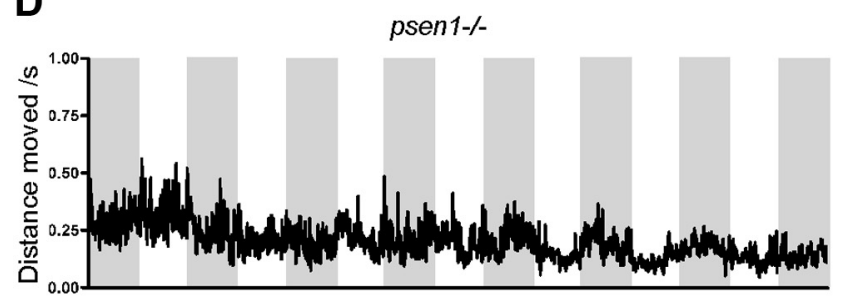

Figure 4. Behavior of larval zebrafish. $A$, Basic locomotor activity is not changed in psen $1^{-1-}$ fish compared with WT fish at $5 \mathrm{dpf}$. Mean values \pm SEM $(n=17-21, p>0.05$, Student's $t$ test). $\boldsymbol{B}$, At $7 \mathrm{dpf}$ the $p s e n 1^{-1-}$ fish move significantly less than WT fish. Mean values \pm SEM (WT $n=62, p s e n 1^{-l-} n=128,{ }^{* * *} p \leq 0.001$, Student's $t$ test). C, Darkinduced flash response in WT larvae at $6 \mathrm{dpf}$. Mean values without standard errors are indicated in the graphs $(n=11) . \boldsymbol{D}$, psen $1^{-/-}$larvae fail to respond consistently to darkness and lack a dark-induced flash response at $6 \mathrm{dpf}$. Mean values without standard errors are indicated in the graphs $(n=9)$.

difference between WT and mutant line at $7 \mathrm{dpf}$ (Fig. 3B). To ensure that the effect seen was specific to the histaminergic system and not a general defect, we also studied the dopaminergic, serotonergic, and galaninergic neurotransmitter systems. Tyrosine hydroxylase 1 immunohistochemistry did not reveal any major difference in the dopaminergic neuron populations (Fig. 3C) between WT and mutant fish at $7 \mathrm{dpf}$. Galanin mRNA, as observed by quantitative RT-PCR, was also unchanged between the mutant and WT (results not shown), as was the expression of the galanin peptide at $7 \mathrm{dpf}$ (Fig. 3D). Both serotonin (Fig. 3E) and galanin (Fig. $3 F$ ) immunoreactivity in the posterior hypothalamus was unaltered between genotypes in adult animals. These results show that the $p \operatorname{sen} 1^{-1-}$ affects specifically the development and maturation of the histaminergic system.

\section{Behavior}

Histamine is known to mediate several behaviors that are altered in $\mathrm{AD}$. Here we studied a repertoire of behaviors that have earlier been documented as histamine dependent (Peitsaro et al., 2003; Peitsaro et al., 2007; Sundvik et al., 2011).

In larvae, we started by assessing the basic locomotor activity. At $5 \mathrm{dpf}$, when there was no difference in the number of histamine neurons (Fig. 2), there was also no difference in the distance 
A

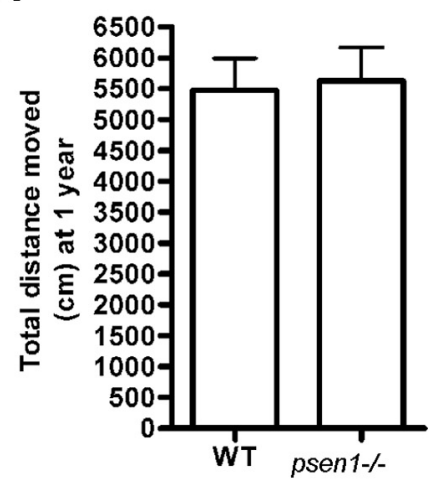

B

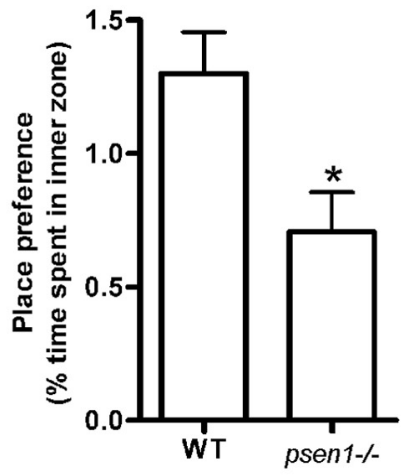

C

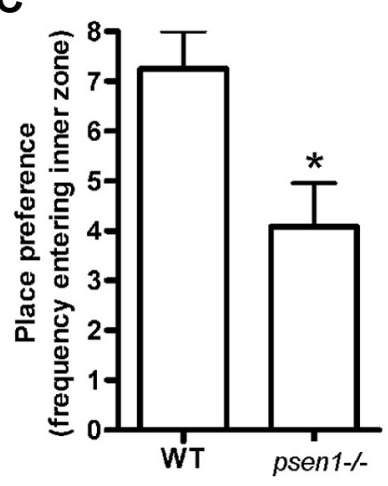

D

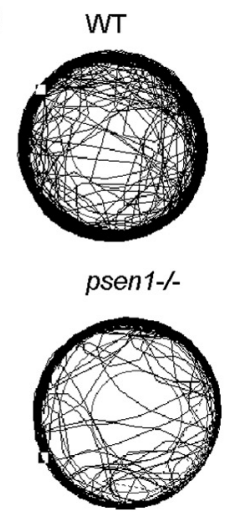

Figure 5. Behavior of adult zebrafish. $\boldsymbol{A}$, Basic locomotor activity is not different in WT and $p$ sen $1^{-/-}$adult fish. $\boldsymbol{B}$, Place preference of $p$ sen $1^{-/-}$fish compared with WT fish is altered, rendering the psen $1^{-1-}$ fish less willing to enter the inner zone of an arena, expressed as time spent in inner zone. $\boldsymbol{C}$, The frequency of entering the inner zone is also reduced in $p$ sen $1^{-1-}$ fish compared with WT fish. Mean values \pm SEM are indicated in all graphs $\left(n=13-16,{ }^{*} p \leq 0.01\right.$, Student's $t$ test). $D$, Characteristic swim tracks of two individual fish.

moved between psen 1 mutants and control larvae (Fig. 4A). At 7 $\mathrm{dpf}$, an age when histamine neuron numbers were decreased in the mutant fish (Fig. 2), we observed also a decrease in total distance moved in psen $^{-/-}$fish (Fig. $4 B$ ). The place preference of the larval zebrafish was altered, and $p s e n 1^{-1-}$ spent more time in the inner zone of the arena compared with WT siblings at $5 \mathrm{dpf}$ $(p \leq 0.01$, Student's $t$ test; mean \pm SEM of WT, $18.79 \pm 3.486$, $n=18$; mean \pm SEM of psen $1^{-/-}$larvae, 38.49 $\pm 5.859, n=16$ ), although no significant change in histamine neuron number was observed. At $7 \mathrm{dpf}$, when the psen $1^{-/-}$larvae showed a reduction in locomotor activity, the mutants showed a preference for the edges of the arena as they avoided the inner zone $(p \leq 0.05$, Student's $t$ test; mean \pm SEM of WT, $33.42 \pm 6.453, n=18$; mean \pm SEM of psen $1^{-1-}$ larvae, $\left.15.52 \pm 4.389, n=16\right)$. Hence, either the lower number of histamine neurons or the reduced spontaneous locomotion affected the place preference at $7 \mathrm{dpf}$. Since the histamine neuron number was lower in $p s e n 1^{-1-}$ at a young age, we assessed the response of larvae to short pulses of dark and light, and found that $p s e n 1^{-1-}$ fish responded in the same manner as $h d c$-deficient zebrafish (Sundvik et al., 2011). The $h d c$-deficient fish lack histamine almost completely (Sundvik et al., 2011), whereas the psen 1 mutants displayed a significant decrease in histamine neuron number. This difference might explain why the dark-induced flash response was partially absent in the $p s e n 1^{-1-}$ fish (Fig. 4C,D, repeated measures two-way ANOVA, $p=0.0014 ; F=1.72, \mathrm{DF} n=50, \mathrm{DF} d=2300$ for the initial dark-induced flash response). The locomotor activity, i.e., total distance moved, of adult $p$ sen $1^{-/-}$zebrafish was not different in comparison to the WT fish (Fig. 5A). The $p s e n 1^{-1-}$ fish exhibited, however, a difference from control fish in their place preference: they avoided the inner zone of the tank (Fig. $5 B$ ). Also, the frequency of entering the inner zone was altered as psen $1^{-1-}$ adult fish entered the inner zone of the tank significantly fewer times than adult WT fish (Fig. 5C). This was also observed when the movement pattern of the fish was studied. Representative tracks of the movement are presented (Fig. 5D).

\section{Development of histaminergic system is dependent on $\gamma$-secretase activity}

psen1 is thought to mainly affect Notch signaling during development in zebrafish as psen 1 morphants exhibit a similar phenotype as that observed in Notch pathway mutants (Nornes et al., $2008,2009)$. Inhibition of the $\gamma$-secretase complex by DAPT has therefore been used in several reports to modify the Notch sig-
A
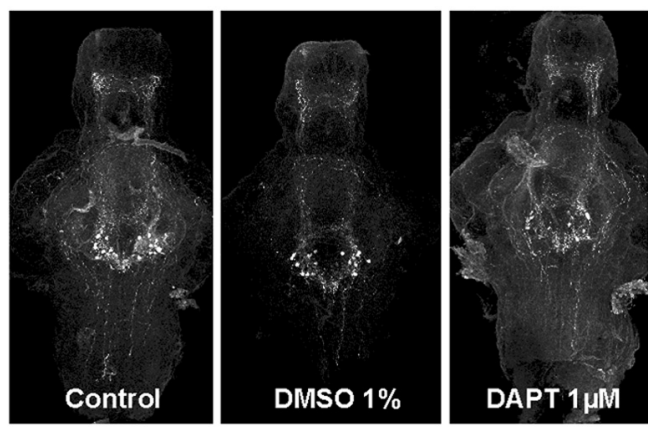

B

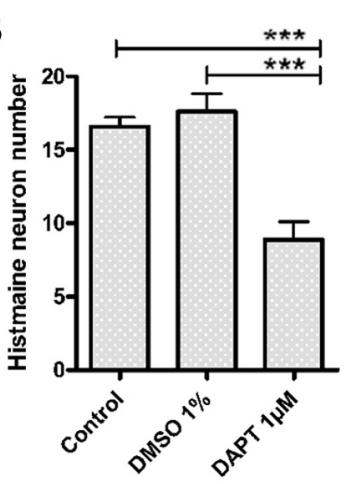

C

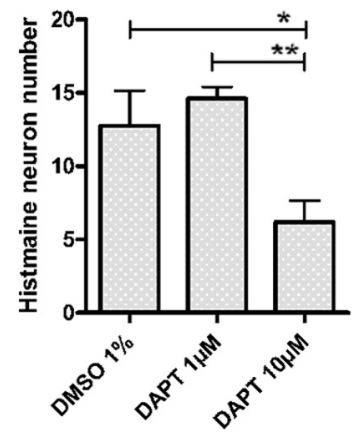

Figure 6. $\gamma$-Secretase inhibitor DAPT impairs the development of the histaminergic neurons. $\boldsymbol{A}$, Treatment of zebrafish larvae from $1-5 \mathrm{dpf}$ with DAPT impaired the development of histaminergic neurons as visualized with immunohistochemistry. $\boldsymbol{B}$, Quantification reviled significantly fewer histamine neurons following DAPT treatment of WT larvae. Mean values \pm SEM ( $n=7-10,{ }^{* * *} p \leq 0.001$, one-way ANOVA, Tukey's post hoc test). C, Also a shorter treatment $(48 \mathrm{~h}$ ) with DAPT at a later stage of development, from $6-8 \mathrm{dpf}$, impaired the development of histamine neurons $\left(n=8-10,{ }^{*} p \leq 0.05,{ }^{* *} p \leq 0.01\right.$, one-way ANOVA, Tukey's post hoc test). All graphs show mean values \pm SEM.

naling pathway (Nornes et al., 2009; Yang et al., 2010, Dias et al., 2012). We found that inhibiting the activity of $\gamma$-secretase with 1 $\mu \mathrm{M}$ DAPT from 1-5 dpf affects the development of the histaminergic neurons. The histamine neuron number was lower in DAPT-treated animals than nontreated animals or those treated with the solute of DAPT, DMSO (Fig. 6A). Quantification revealed significantly fewer histamine neurons following DAPT treatment ${ }^{* * *} p \leq 0.001$, one-way ANOVA, Tukey's post hoc test) compared with both untreated control and DMSO-treated larvae (Fig. $6 \mathrm{~B})$. Also, a shorter treatment $(48 \mathrm{~h})$ with a higher dose of 

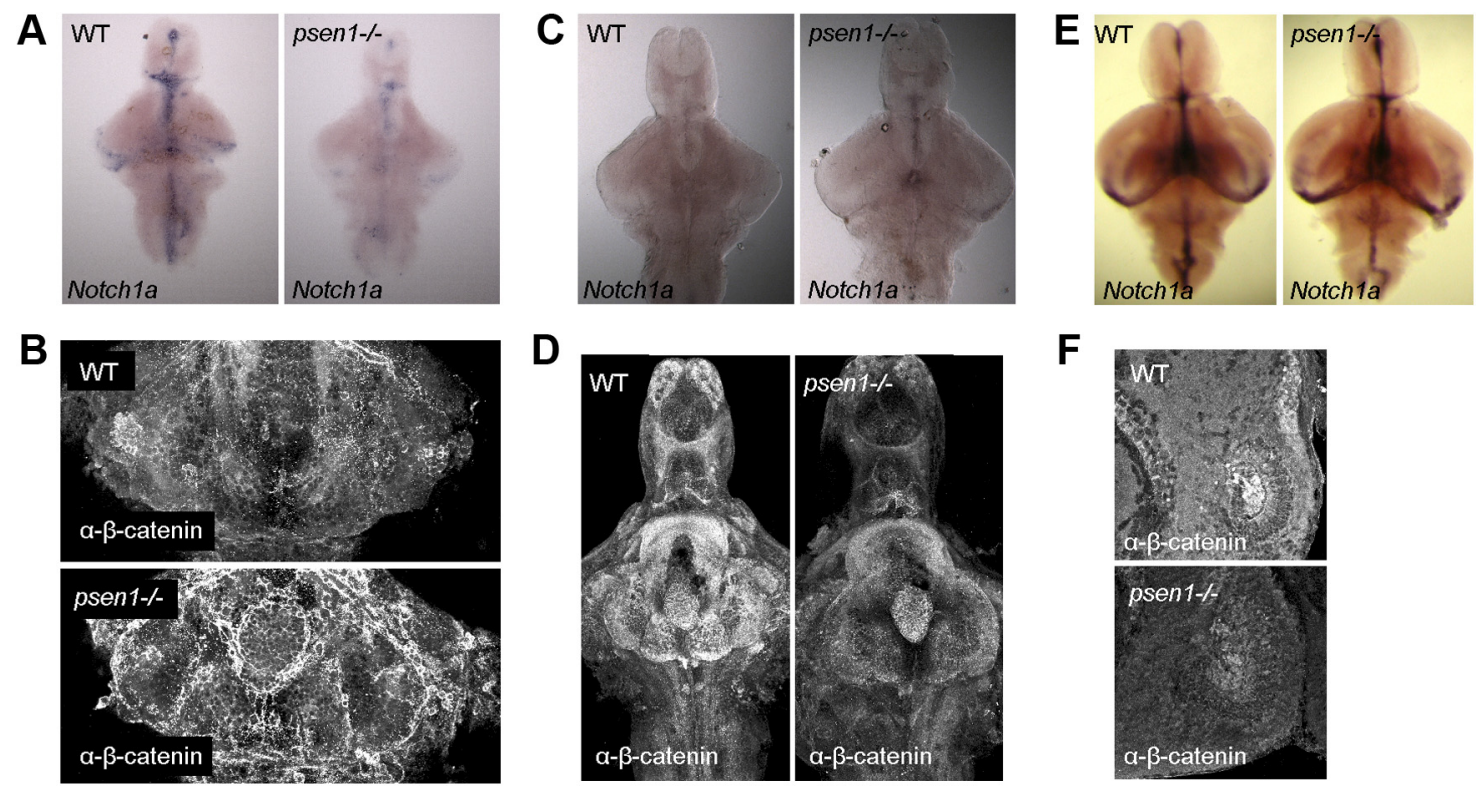

Figure 7. Signaling pathways affected by $\gamma$-secretase. $\boldsymbol{A}, \boldsymbol{B}$, Reduced Notch $1 a$ mRNA $(\boldsymbol{A})$ and increased $\beta$-catenin $(\boldsymbol{B})$ immunoreactivity in $7 \mathrm{dpf}$ psen $1^{-/-}$larvae when compared with WT fish. $n=6-9$ /group. $\boldsymbol{C}, \boldsymbol{D}$, Increased Notch1a mRNA ( $\boldsymbol{C}$ ) and reduced $\beta$-catenin (D) immunoreactivity at $14 \mathrm{dpf}$ in psen $1^{-1-}$ larvae when compared with WT fish. $\boldsymbol{E}, \boldsymbol{F}$, At 1 month of age the Notch $1 a$ mRNA expression pattern and intensity were similar in the two groups $(\boldsymbol{E})$, whereas at $\sim 2.5$ years the $\beta$-catenin immunoreactivity was lower in the posterior hypothalamus of the psen $1^{-I-}$ animals compared with WT animals $(\boldsymbol{F}) ; n=4-7 /$ group in $\boldsymbol{C}-\boldsymbol{F}$.

DAPT $(10 \mu \mathrm{M})$ at a later stage of development, from 6-8 dpf, impaired the development of histamine neurons compared with DMSO control group $\left(^{\star} p \leq 0.05,{ }^{\star *} p \leq 0.01\right.$, one-way ANOVA, Tukey's post hoc test, Fig. $6 \mathrm{C}$ ). Although there were significantly fewer histamine neurons in the animals treated with DAPT, the smaller number of neurons did not cause an impairment of the dark-induced flash response (repeated measures two-way ANOVA, $p=0.7183, F=0.91, \mathrm{DF} n=98, \mathrm{DF} d=1519)$ when compared with WT animals. The reduction of the number of histamine neurons obtained with DAPT treatment (1-5 dpf) was not as large as that seen in $p \operatorname{sen} 1^{-1-}$ mutants. Notch and Wnt/ $\beta$-catenin are major signaling pathways important during embryonic development and in the adult brain (Inestrosa and Arenas, 2010; Ables et al., 2011). PSEN1 is necessary for degradation of $\beta$-catenin (Kang et al., 2002), and an impairment of PSEN1 function causes an increase in $\beta$-catenin (Xia et al., 2001). We therefore assessed further the expression of Notch1a mRNA by in situ hybridization and $\beta$-catenin immunoreactivity in $7 \mathrm{dpf}$ larval brains, as both signaling pathways are regulated by $\gamma$-secretase function. Notch1a mRNA was strongly reduced in the $p \operatorname{sen} 1^{-1-}$ larval brains compared with the level observed in WT zebrafish brains (Fig. 7A). Immunohistochemistry of $\beta$-catenin, revealed an increase in the $\beta$-catenin immunoreactivity in hypothalamus of $p s e n 1^{-1-}$ fish compared with WT fish (Fig. 7B). At $14 \mathrm{dpf}$, Notch 1 a mRNA was slightly increased in the $p s e n 1^{-1-}$ animals compared with WT fish (Fig. $7 C$ ), and finally at 1 month of age the Notch 1 a mRNA was similarly expressed in both genotypes (Fig. $7 E$ ). The $\beta$-catenin immunoreactivity was reduced in psen $1^{-1-}$ animals compared with WT animals at $14 \mathrm{dpf}$ (Fig. $7 D$ ), and the same effect was observed in the posterior hypothalamus of adult $p \operatorname{sen} 1^{-1-}$ animals when compared with WT animals (Fig. $7 F$ ). Taken together, these results indicate that $\gamma$-secretase activity is essential for the development of histaminergic neurons.

\section{Discussion}

We found that, in a zebrafish mutant carrying a premature stop codon in the $p \operatorname{sen} 1$ gene, the histaminergic neurotransmitter sys- tem was significantly altered during the development and in adulthood. The change in the histamine system had measurable behavioral consequences in both larval and adult zebrafish. In agreement with these findings, we found that a dysfunctional $\gamma$-secretase complex regulates the development of histaminergic neurons via Notch signaling.

The ortholog of human PSEN1 in zebrafish was identified over a decade ago (Leimer et al., 1999). In contrast to psen 1 knockout mice, which die at birth (Shen et al., 1997), psen $1^{-1-}$ mutant zebrafish are viable and fertile. Unlike the psen 1 knockout mice, which have major skeletal and CNS deficits (Shen et al., 1997), we did not observe any major defects in the gross morphology of $p s e n 1^{-1-}$ zebrafish in comparison with WT zebrafish. Inhibition of psen 1 function in zebrafish with morpholino oligonucleotides (MOs) induces defective brain development (Nornes et al., 2003). Transient disruption of psen 2 function with a MO has been suggested to have a stronger effect on Notch signaling in zebrafish embryos compared with mammals (Nornes et al., 2009). This might explain why the $p \operatorname{sen} 1^{-1-}$ zebrafish does not show the same gross morphology as psen 1 knockout mice. The cholinergic neurotransmitter system is profoundly affected in AD patients (Whitehouse et al., 1982). Several postmortem studies have shown that other systems are also affected in brains of AD patients, including the histamine system in which a reduction in histamine levels (Panula et al., 1998) and accumulation of neurofibrillary tangles (Saper and German, 1987; Airaksinen et al., 1991) have been observed. We found that at a young age psen $1^{-1-}$ zebrafish had fewer histaminergic neurons compared with WT zebrafish, and this was associated with a disruption in a specific histamine-mediated behavioral response. The $p \operatorname{sen} 1^{-1-}$ larval fish were less observant of their environment and did not consistently exhibit the dark-induced flash response as did WT larvae. These results are supported by previous studies that show that histamine is a wakefulness promoting factor, a mediator of vigilance and cognitive performance (Haas and Panula, 2003; Haas et al., 2008; Sundvik et al., 2011). Cognitive impairments are 
a major health risk and have a multifaceted etiology closely associated with aging in humans. The brains of psen 1 knockout mice are significantly smaller (Shen et al., 1997), a result indicative of an impairment of neurogenesis and neuronal proliferation in psen 1 deficient animals. We found that in $p s e n 1^{-1-}$ fish the Notch1 a mRNA expression was reduced compared with WT controls. In WT fish, $\gamma$-secretase inhibitor DAPT induced the same phenotype as that observed in $p s e n 1^{-1-}$ fish; there were fewer histaminergic neurons at the developmental stage when psen $1^{-1-}$ and/or DAPT-treated fish were compared with WT and/or control. Nevertheless, DAPT treatment did not abolish the dark-induced flash response as in $p s e n 1^{-1-}$ mutants or in $h d c$ morphants (Sundvik et al., 2011). This is likely due to a smaller reduction in histamine cell numbers than that seen in $p s e n 1^{-1-}$ mutants or $h d c$ morphants, but the role of unidentified additional factors cannot be excluded. This is, to our knowledge, the first report that describes a factor that affects the development of histaminergic neurons. The intracellular domain of Notch functions as a transcription factor and is essential in the early development as noted for the first time a century ago (reviewed in Artavanis-Tsakonas et al., 1999). We detected Notch1a mRNA along the midline rostrocaudal axis in the telencephalic ventricular zone, hypothalamus, and cerebellum of the zebrafish brain at 7,14 , and $28 \mathrm{dpf}$. These regions are the neurogenic and proliferative regions of the zebrafish brain (Kaslin et al., 2008; Kizil et al., 2011). In the psen $1^{-1-}$ zebrafish the expression of Notch1a mRNA in these zones was strongly reduced at $7 \mathrm{dpf}$, suggesting an alteration of neurogenesis and proliferation. The abnormalities in the histaminergic system were likely due to an impairment of the neurogenesis and/or proliferation rather than cell death in the psen $1^{-1-}$ fish, because we did not observe increased activation of caspase- 3 in the mutants. Furthermore, we assessed other neurotransmitter systems (dopaminergic, serotonergic, and galaninergic) in the $p \operatorname{sen} 1^{-1-}$ and WT fish to ensure that the effect observed was specific to the histaminergic neurotransmitter system and not a general effect on several neurotransmitter systems. Notch and Wnt/ $\beta$-catenin signaling are involved in development of the dopaminergic system in zebrafish (Mahler et al., 2010), but we did not observe any major difference in the dopaminergic neurotransmitter system between the studied genotypes. Taken together, these results show that the phenotype of the $p s e n 1^{-1-}$ fish is partially similar to that reported for $p s e n 1^{-/-}$mammalian models (reduced notch1 signaling, Jack et al., 2001) and increased $\beta$-catenin (Xia et al., 2001), and partially similar to the results for psen $1 \mathrm{MO}$-treated zebrafish embryos (van Tijn et al., 2011), as the Notch signaling pathway was altered in both zebrafish models. Intriguingly, we thereby found that the development of the histaminergic neurons is mediated by $\gamma$-secretase and most likely via Notch signaling. We then went on to assess the histaminergic system in the adult $p s e n 1^{-/-}$zebrafish, as neurodegenerative diseases such as $\mathrm{AD}$ manifest in late life and the whole pathology may not be apparent during early development. We found that in young adult $p \operatorname{sen} 1^{-1-}$ zebrafish the histaminergic neuron number was significantly increased compared with WT control fish, whereas the serotonergic and galaninergic systems were unaltered at adult age. This change in neuron number was associated with a histamine-mediated behavior previously reported for adult zebrafish (Peitsaro et al. 2003), as we found that fish with higher histamine neuron numbers had an altered place preference when placed in an open arena. These individuals preferred to spend the time close to the edges of the arena. Adult zebrafish with reduced brain histamine level after treatment with $\alpha$-FMH ( $\alpha$-fluoromethylhistidine, an inhibitor of the histamine- producing enzyme HDC) also exhibit an altered place preference, as they spend more time in the middle of an open arena compared with saline-injected control animals (Peitsaro et al., 2003). Therefore, the increase in histamine neuron numbers in the adult psen $1^{-/-}$zebrafish is most likely accountable for this specific change in place preference. Although no significant difference in histamine neuron number was observed at $5 \mathrm{dpf}$, there was a difference in place preference behavior between the mutants and control fish, suggesting that already a subtle change in network balance can affect behavior. At this time it is not possible to exclude the role of other, unknown contributing factors unrelated to histamine. Since the reduced number of histamine neurons in $7 \mathrm{dpf}$ fish and the increased number of neurons in adult fish were both associated with increased thigmotaxis, the mechanism of thigmotaxis may be different in larvae and adults. In adults it has been shown to be histamine dependent (Peitsaro et al. 2003). The mechanism underlying this increase in histamine neuron number in adult $p s e n 1^{-1-}$ zebrafish is unknown, but it could be due to a change in proliferation or neurotransmitter respecification.

These results shed new light on the role of psen 1, an important disease gene, in neurogenesis of an essential transmitter phenotype. The study identifies psen 1 as a key regulator of histaminergic neuron development. The results reveal a life-long brain plasticity in both the structure of the histaminergic system and its functions induced by altered Notch 1 activity as a consequence of $p s e n 1$ mutation. A related Notch1-dependent mechanism has been previously associated with damage-induced regeneration of motoneurons (Dias et al., 2012). The new histaminergic neurons in aging zebrafish brain may arise as a result of phenotypic plasticity (Spitzer, 2012) or represent newly differentiated stem cells. This study also shows the importance of studying adult animals in addition to developmental stages in characterization of phenotypes of disease gene mutants.

\section{References}

Ables JL, Breunig JJ, Eisch AJ, Rakic P (2011) Not(ch) just development: Notch signalling in the adult brain. Nat Rev Neurosci 12:269-283. CrossRef Medline

Airaksinen MS, Paetau A, Paljärvi L, Reinikainen K, Riekkinen P, Suomalainen R, Panula P (1991) Histamine neurons in human hypothalamus: anatomy in normal and Alzheimer diseased brains. Neuroscience 44:465-481. CrossRef Medline

Artavanis-Tsakonas S, Rand MD, Lake RJ (1999) Notch signaling: Cell fate control and signal integration in development. Science 284:770-776. CrossRef Medline

Bishop NA, Lu T, Yankner BA (2010) Neural mechanisms of ageing and cognitive decline. Nature 464:529-535. CrossRef Medline

Borchelt DR, Thinakaran G, Eckman CB, Lee MK, Davenport F, Ratovitsky T, Prada CM, Kim G, Seekins S, Yager D, Slunt HH, Wang R, Seeger M, Levey AI, Gandy SE, Copeland NG, Jenkins NA, Price DL, Younkin SG, Sisodia SS (1996) Familial Alzheimer's disease-linked presenilin 1 variants elevate A $\beta 1-42 / 1-40$ ratio in vitro and in vivo. Neuron 17:10051013. CrossRef Medline

Chen YC, Priyadarshini M, Panula P (2009) Complementary developmental expression of the two tyrosine hydroxylase transcripts in zebrafish. Histochem Cell Biol 132:375-381. CrossRef Medline

Dale HH, Laidlaw PP (1910) The physiological action of $\beta$-iminazolylethylamine. J Physiol 41:318-344. Medline

De Strooper B, Annaert W (2010) Novel research horizons for presenilins and gamma-secretases in cell biology and disease. Annu Rev Cell Dev Biol 26:235-260. CrossRef Medline

De Strooper B, Annaert W, Cupers P, Saftig P, Craessaerts K, Mumm JS, Schroeter EH, Schrijvers V, Wolfe MS, Ray WJ, Goate A, Kopan R (1999) A presenilin-1-dependent $\gamma$-secretase-like protease mediates release of Notch intracellular domain. Nature 398:518-522. CrossRef Medline

Dias TB, Yang YJ, Ogai K, Becker T, Becker CG (2012) Notch signaling 
controls generation of motor neurons in the lesioned spinal cord of adult zebrafish. J Neurosci 32:3245-3252. CrossRef Medline

Dillen K, Annaert W (2006) A two decade contribution of molecular cell biology to the centennial of Alzheimer's disease: Are we progressing toward therapy? Int Rev Cytol 254:215-300. CrossRef Medline

Ekström P, Holmqvist BI, Panula P (1995) Histamine-immunoreactive neurons in the brain of the teleost Gasterosteus aculeatus L. correlation with hypothalamic tyrosine hydroxylase- and serotonin-immunoreactive neurons. J Chem Neuroanat 8:75-85. CrossRef Medline

Eriksson KS, Peitsaro N, Karlstedt K, Kaslin J, Panula P (1998) Development of the histaminergic neurons and expression of histidine decarboxylase mRNA in the zebrafish brain in the absence of all peripheral histaminergic systems. Eur J Neurosci 10:3799-3812. CrossRef Medline

Guo Q, Furukawa K, Sopher BL, Pham DG, Xie J, Robinson N, Martin GM, Mattson MP (1996) Alzheimer's PS-1 mutation perturbs calcium homeostasis and sensitizes PC12 cells to death induced by amyloid betapeptide. Neuroreport 8:379-383. CrossRef Medline

Haas H, Panula P (2003) The role of histamine and the tuberomamillary nucleus in the nervous system. Nat Rev Neurosci 4:121-130. CrossRef Medline

Haas HL, Sergeeva OA, Selbach O (2008) Histamine in the nervous system. Physiol Rev 88:1183-1241. CrossRef Medline

Hansson CA, Frykman S, Farmery MR, Tjernberg LO, Nilsberth C, Pursglove SE, Ito A, Winblad B, Cowburn RF, Thyberg J, Ankarcrona M (2004) Nicastrin, presenilin, APH-1, and PEN-2 form active gamma-secretase complexes in mitochondria J Biol Chem 279:51654-51660. CrossRef Medline

Inestrosa NC, Arenas E (2010) Emerging roles of wnts in the adult nervous system. Nat Rev Neurosci 11:77-86. CrossRef Medline

Jack C, Berezovska O, Wolfe MS, Hyman BT (2001) Effect of PS1 deficiency and an APP $\gamma$-secretase inhibitor on Notch1 signaling in primary mammalian neurons. Brain Res Mol Brain Res 87:166-174. CrossRef Medline

Kang DE, Soriano S, Xia X, Eberhart CG, De Strooper B, Zheng H, Koo EH (2002) Presenilin couples the paired phosphorylation of beta-catenin independent of axin: Implications for beta-catenin activation in tumorigenesis. Cell 110:751-762. CrossRef Medline

Kaslin J, Panula P (2001) Comparative anatomy of the histaminergic and other aminergic systems in zebrafish (Danio rerio). J Comp Neurol 440: 342-377. CrossRef Medline

Kaslin J, Ganz J, Brand M (2008) Proliferation, neurogenesis and regeneration in the non-mammalian vertebrate brain. Philos Trans R Soc Lond B Biol Sci 363:101-122. CrossRef Medline

Keegan BR, Feldman JL, Lee DH, Koos DS, Ho RK, Stainier DY, Yelon D (2002) The elongation factors Pandora/Spt6 and Foggy/Spt5 promote transcription in the zebrafish embryo. Development 129:1623-1632. Medline

Kimberly WT, LaVoie MJ, Ostaszewski BL, Ye W, Wolfe MS, Selkoe DJ (2003) Gamma-secretase is a membrane protein complex comprised of presenilin, nicastrin, Aph-1, and Pen-2 Proc Natl Acad Sci U S A 100: 6382-6387. CrossRef

Kizil C, Kaslin J, Kroehne V, Brand M (2011) Adult neurogenesis and brain regeneration in zebrafish. Dev Neurobiol 72:429-461. CrossRef Medline

Kovacs DM, Fausett HJ, Page KJ, Kim TW, Moir RD, Merriam DE, Hollister RD, Hallmark OG, Mancini R, Felsenstein KM, Hyman BT, Tanzi RE, Wasco W (1996) Alzheimer-associated presenilins 1 and 2: neuronal expression in brain and localization to intracellular membranes in mammalian cells. Nat Med 2:224-229. Medline

Kratz E, Eimon PM, Mukhyala K, Stern H, Zha J, Strasser A, Hart R, Ashkenazi A (2006) Functional characterization of the $B c l-2$ gene family in the zebrafish. Cell Death Differ 13:1631-1640. CrossRef Medline

Kudo H, Liu J, Jansen EJ, Ozawa A, Panula P, Martens GJ, Lindberg I (2009) Identification of proSAAS homologs in lower vertebrates: conservation of hydrophobic helices and convertase-inhibiting sequences. Endocrinology 150:1393-1399. CrossRef Medline

Leimer U, Lun K, Romig H, Walter J, Grünberg J, Brand M, Haass C (1999) Zebrafish (Danio rerio) presenilin promotes aberrant amyloid $\beta$-peptide production and requires a critical aspartate residue for its function in amyloidogenesis. Biochemistry 38:13602-13609. CrossRef Medline

Levitan D, Greenwald I (1995) Facilitation of lin-12-mediated signalling by sel-12, a Caenorhabditis elegans S182 Alzheimer's disease gene. Nature 377:351-354. CrossRef Medline

Mahler J, Filippi A, Driever W (2010) DeltaA/DeltaD regulate multiple and temporally distinct phases of Notch signaling during dopaminergic neurogenesis in zebrafish. J Neurosci 30:16621-16635. CrossRef Medline

Matsuda M, Chitnis AB (2009) Interaction with notch determines endocytosis of specific delta ligands in zebrafish neural tissue. Development 136 : 197-206. CrossRef Medline

Medhurst AD, Atkins AR, Beresford IJ, Brackenborough K, Briggs MA, Calver AR, Cilia J, Cluderay JE, Crook B, Davis JB, Davis RK, Davis RP, Dawson LA, Foley AG, Gartlon J, Gonzalez MI, Heslop T, Hirst WE, Jennings C, Jones DN, et al. (2007) GSK189254, a novel H3 receptor antagonist that binds to histamine $\mathrm{H} 3$ receptors in Alzheimer's disease brain and improves cognitive performance in preclinical models. J Pharmacol Exp Ther 321:1032-1045. CrossRef Medline

Molina-Hernández A, Velasco I (2008) Histamine induces neural stem cell proliferation and neuronal differentiation by activation of distinct histamine receptors. J Neurochem 106:706-717. CrossRef Medline

Nornes S, Groth C, Camp E, Ey P, Lardelli M (2003) Developmental control of Presenilin1 expression, endoproteolysis, and interaction in zebrafish embryos. Exp Cell Res 289:124-132. CrossRef Medline

Nornes S, Newman M, Verdile G, Wells S, Stoick-Cooper CL, Tucker B, Frederich-Sleptsova I, Martins R, Lardelli M (2008) Interference with splicing of presenilin transcripts has potent dominant negative effects on presenilin activity. Hum Mol Genet 17:402-412. CrossRef Medline

Nornes S, Newman M, Wells S, Verdile G, Martins RN, Lardelli M (2009) Independent and cooperative action of Psen2 with Psen1 in zebrafish embryos. Exp Cell Res 315:2791-2801. CrossRef Medline

Panula P, Yang HY, Costa E (1984) Histamine-containing neurons in the rat hypothalamus. Proc Natl Acad Sci U S A 81:2572-2576. CrossRef Medline

Panula P, Airaksinen MS, Pirvola U, Kotilainen E (1990) A histaminecontaining neuronal system in human brain. Neuroscience 34:127-132. CrossRef Medline

Panula P, Rinne J, Kuokkanen K, Eriksson KS, Sallmen T, Kalimo H, Relja M (1998) Neuronal histamine deficit in Alzheimer's disease. Neuroscience 82:993-997. CrossRef Medline

Panula P, Sallinen V, Sundvik M, Kolehmainen J, Torkko V, Tiittula A, Moshnyakov M, Podlasz P (2006) Modulatory neurotransmitter systems and behavior: towards zebrafish models of neurodegenerative diseases. Zebrafish 3:235-247. CrossRef Medline

Panula P, Chen YC, Priyadarshini M, Kudo H, Semenova S, Sundvik M, Sallinen V (2010) The comparative neuroanatomy and neurochemistry of zebrafish CNS systems of relevance to human neuropsychiatric diseases. Neurobiol Dis 40:46-57. CrossRef Medline

Peitsaro N, Kaslin J, Anichtchik OV, Panula P (2003) Modulation of the histaminergic system and behaviour by alpha-fluoromethylhistidine in zebrafish. J Neurochem 86:432-441. CrossRef Medline

Peitsaro N, Sundvik M, Anichtchik OV, Kaslin J, Panula P (2007) Identification of zebrafish histamine $\mathrm{H} 1, \mathrm{H} 2$ and $\mathrm{H} 3$ receptors and effects of histaminergic ligands on behavior. Biochem Pharmacol 73:1205-1214. CrossRef Medline

Rodríguez JJ, Jones VC, Verkhratsky A (2009) Impaired cell proliferation in the subventricular zone in an Alzheimer's disease model. Neuroreport 20:907-912. CrossRef Medline

Saper CB, German DC (1987) Hypothalamic pathology in Alzheimer's disease. Neurosci Lett 74:364-370. CrossRef Medline

Schwartz JC (2011) The histamine H3 receptor: from discovery to clinical trials with pitolisant. Br J Pharmacol 163:713-721. CrossRef Medline

Serban G, Kouchi Z, Baki L, Georgakopoulos A, Litterst CM, Shioi J, Robakis NK (2005) Cadherins mediate both the association between PS1 and $\beta$-catenin and the effects of PS1 on $\beta$-catenin stability J Biol Chem 280: 36007-36012. CrossRef Medline

Shen J, Bronson RT, Chen DF, Xia W, Selkoe DJ, Tonegawa S (1997) Skeletal and CNS defects in presenilin-1-deficient mice. Cell 89:629-639. CrossRef Medline

Spitzer NC (2012) Activity-dependent neurotransmitter respecification. Nat Rev Neurosci 13:94-106. CrossRef Medline

Stutzmann GE, Caccamo A, LaFerla FM, Parker I (2004) Dysregulated IP3 signaling in cortical neurons of knock-in mice expressing an Alzheimer'slinked mutation in presenilin1 results in exaggerated $\mathrm{Ca}^{2+}$ signals and altered membrane excitability. J Neurosci 24:508-513. CrossRef Medline

Sundvik M, Panula P (2012) The histaminergic system in zebrafish (Danio rerio) brain: neuron number, location and co-transmitters. J Comp Neurol 520:3827-3845. CrossRef Medline 
Sundvik M, Kudo H, Toivonen P, Rozov S, Chen YC, Panula P (2011) The histaminergic system regulates wakefulness and orexin/hypocretin neuron development via histamine receptor $\mathrm{H} 1$ in zebrafish. FASEB J 25: 4338-4347. CrossRef Medline

Tallafuss A, Trepman A, Eisen JS (2009) DeltaA mRNA and protein distribution in the zebrafish nervous system. Dev Dyn 238:3226-3236. CrossRef Medline

Tanzi RE, Bertram L (2005) Twenty years of the alzheimer's disease amyloid hypothesis: a genetic perspective. Cell 120:545-555. CrossRef Medline

Thisse C, Thisse B (2008) High-resolution in situ hybridization to wholemount zebrafish embryos. Nat Protoc 3:59-69. CrossRef Medline

Tiligada E, Kyriakidis K, Chazot PL, Passani MB (2011) Histamine pharmacology and new CNS drug targets. CNS Neurosci Ther 17:620-628. CrossRef Medline

van Tijn P, Kamphuis W, Marlatt MW, Hol EM, Lucassen PJ (2011) Presenilin mouse and zebrafish models for dementia: focus on neurogenesis. Prog Neurobiol 93:149-164. CrossRef Medline

Veeraraghavalu K, Choi SH, Zhang X, Sisodia SS (2010) Presenilin $1 \mathrm{mu}-$ tants impair the self-renewal and differentiation of adult murine subventricular zone-neuronal progenitors via cell-autonomous mechanisms involving notch signaling. J Neurosci 30:6903-6915. CrossRef Medline

Wen PH, Shao X, Shao Z, Hof PR, Wisniewski T, Kelley K, Friedrich VL Jr, Ho
L, Pasinetti GM, Shioi J, Robakis NK, Elder GA (2002) Overexpression of wild type but not an FAD mutant presenilin-1 promotes neurogenesis in the hippocampus of adult mice. Neurobiol Dis 10:8-19. CrossRef Medline

Whitehouse PJ, Price DL, Struble RG, Clark AW, Coyle JT, Delon MR (1982) Alzheimer's disease and senile dementia: loss of neurons in the basal forebrain. Science 215:1237-1239. CrossRef Medline

Wienholds E, van Eeden F, Kosters M, Mudde J, Plasterk RH, Cuppen E (2003) Efficient target-selected mutagenesis in zebrafish. Genome Res 13:2700-2707. CrossRef Medline

Xia X, Qian S, Soriano S, Wu Y, Fletcher AM, Wang XJ, Koo EH, Wu X, Zheng H (2001) Loss of presenilin 1 is associated with enhanced beta-catenin signaling and skin tumorigenesis. Proc Natl Acad Sci U S A 98:10863-10868. CrossRef Medline

Xu X, Shi YC, Gao W, Mao G, Zhao G, Agrawal S, Chisolm GM, Sui D, Cui MZ (2002) The novel presenilin-1-associated protein is a proapoptotic mitochondrial protein. J Biol Chem 277:48913-48922. CrossRef Medline

Yang T, Arslanova D, Xu X, Li YM, Xia W (2010) In vivo manifestation of notch related phenotypes in zebrafish treated with Alzheimer's amyloid reducing gamma-secretase inhibitors. J Neurochem 113:12001209. CrossRef Medline 